\title{
Havacılıkta Yaygınlaşan Yapay Zeka, API ve Büyük Veri Temelli Çözümler
}

\author{
${ }^{1}$ Didem Çankaya \\ ${ }^{1} \mathrm{TAV}$ Technologies, Istanbul, TR
}

\begin{abstract}
:
With each passing day, artificial intelligence, big data and API technologies accelerate the transformation of the sectors and aviation takes its share from this change. Thanks to the development of these technologies, robots that provide information to passengers, answer their questions and help them have fun are becoming widespread in many airports today as well as the robots can be used in services such as cleaning and security. In addition, traditional systems that do not have direct interaction with the passenger are now increasing their performance with the development of technologies such as machine learning, fuzzy logic, and natural language processing. These technologies and solutions which also contribute to the aviation ecosystem in terms of creating innovation opportunities will also change the rules, expectations and traditions of the sector. Within the scope of this study, the usage areas of the relevant technologies at the airports and their benefits to the passengers were researched.
\end{abstract}

Keywords: Artifical Intelligence, API, Big Data, Digital Transformation, Robots

\section{Özet:}

Her geçen gün yapay zeka, big data ve API teknolojileri sektörlerin değişimini hızlandırmaktadır ve havacılık da bu değişimden payını almaktadır. Bu teknolojilerdeki gelişim sayesinde bugün birçok havalimanında yolculara bilgi veren, sorularını cevaplayan, eğlenmelerine yardımcı olan robotlar yaygınlaştığı gibi temizlik, güvenlik gibi hizmetlerde de robotlar kullanılabilmektedir. Ayrıca, yolcu ile doğrudan etkilişimi olmayan geleneksel sistemler de artık makine öğrenmesi, bulanık mantık, doğal dil işleme gibi teknolojilerin gelişimi ile performanslarını artırmaktadır. Havacılık ekosistemine inovasyon olanağı yaratması yönünden de katkı sağlayan bu teknolojiler ve doğurduğu çözümler sektörün kurallarını, beklentilerini ve geleneklerini de değiştirecektir. Bu çalışma kapsamında ilgili teknolojilerin havalimanlarındaki kullanım alanları ve yolculara sağladığı faydalar araştırılmıştır.

Anahtar Kelimeler: Yapay Zeka, API, Büyük Veri, Dijital Dönüşüm, Robotlar

\section{Giriş}

Yaşadığımız yüzyıl teknoloji çağı olarak nitelendirilmektedir, bu yüzyılda öne çıkan teknolojik gelişmeler, insanların yaşam biçimine yön vermektedir. İnsanlar teknolojik cihazları kullanmanın tatmin ve kolaylığını yaşarken, işletmelerde topladıkları verileri pazarlama amaçları doğrultusunda firsata çevirmektedir. Bu yeni dönemde şirketler rekabete ayak uydurabilmek adına ; pazarlama faaliyetlerini teknolojik gelişmeler doğrultusunda yönlendirmektedirler. Pazarlama ve teknoloji departmanlarının bu dönemdeki işbirlikleri diğer dönemlere kıyasla daha da artmış ve vazgeçilmez olmuştur.

Havacılık sektörü teknolojik gelişmelerde, diğer sektörlere kıyasla öncü konumdadır. Yıldan yıla küreselleşmede meydana gelen artış ile birlikte, havacılık sektörü de hızlı bir büyüme ivmesi

*Corresponding author: Didem Çankaya Address: Ayazağa Mahallesi Vadistanbul Bulvar, Cendere Caddesi, No: 109L, D:2C Blok, 34485 Sarıer E-mail address: didem.cankaya@ tav.aero 
kaydetmektedir. Yolcu sayısı, sektörün temel kazanç birimidir. Öyle ki ; sektöre yön veren kurumlar (havayolu firmaları, havalimanı işletmecileri gibi) yıllık gelirlerinin tamamını doğru ya da dolaylı olarak yolcu sayısı üzerinden belirlerler [1].

Yolcunun ihtiyaçları doğrultusunda dijital dönüşüme odaklanan işletmeler ; farklı formlarda ve alanlardaki teknolojik gelişmelerin de takipçisi olurlar ; Bıg Data, API - Yazılım Programlama Arayüzü, Yapay Zeka bu teknolojik gelişmelere verilebilecek bazı örneklerdir. Bu teknolojilerin her biri dijital dönüşümün bir parçası ve aynı zamanda yolcuya seyahati sırasında kritik noktalardan değen inovatif yapı taşlarıdır.

\section{Dijital Dönüşüm Potansiyeli Yaratan Teknolojiler}

\subsection{Büyük Veri}

Endüstri analisti Doug Laney 2000'li yılların başında büyük veri kavramını 3V üzerinden tanımlamıştır ; Volume (hacim), Variety (çeşitlilik) ve Velocity (hız) [2]. Bu tanımdaki verinin hacmi ; işletmelerin akıllı cihaz, video, sosyal medya ve farklı ekipmanlar aracılığı ile toplanan verinin büyüklüğüdür. Verinin çeşitliliği ; sayısal verilerden, metinlere, e-postalardan, video ve ses dosyalarına kadar birçok çeşitli veri yapılarının bütünüdür. Verinin hızı; veriler işletmelere hızlı bir şekilde ulaşır ve işletmeler de bu verileri neredeyse gerçek zamanlı bir şekilde çok hızlı işlerler.

Havacılık sektörü açısından değerlendirdiğimizde büyük veri kapsamında online rezervasyon, biletleme işlemleri, uçuş öncesi ve uçuş sonrası gibi bilgiler büyük veri olarak değerlendirilebilir. [3]. Bu verilerin toplanmasındaki amaç; uçuşların, yolcuların davranış ve tercihlerinin önceden tahmin edilmesinin sağlanması ve pazarlama faaliyetleri ile birleştirilmesidir. Böylece sektördeki işletmelerin gelirinde artış sağlanabilir. Yolcuların uçuş verilerinden yeme-içme, alışveriş vb alanlarda davranışsal verilerine kadar bilgi sahibi olunabilir, bu bilgiler doğru işlenirse gelirin artmasına dönüştürülebilir. Gelirlerdeki bu artış ve işletmelerin bu yenilikçi pazarlama faaliyetleri ; paydaşlarda değer artışı, müşteri tatmini, yeni ürün ve hizmetlerin hatta belki yeni bir pazarın yaratılma firsatı, sektörde öncü olunması gibi artı değerler sağlamaktadır.

"Büyük Veri” çok sayıda paydaşın katılım sağladığı havalimanı operasyonlarında yolcu, bagaj ve uçuş tahminlemeleri gibi yapay zeka uygulamaları için de büyük önem taşımaktadır.

\subsection{API - Yazılım (Uygulama) Programlama Arayüzü}

Uygulama Programlama Arayüzü ; bir işletmeden gelen verilerin kontrollü bir şekilde kullanılarak bütün veya bazı bilgilerinin diğer uygulamalarda kullanıma açılması ve taleplerinin karşılanmasıdır. Bu şekilde bir tek uygulama üzerinden gerçekleşecek olan işlem verileri, kontrollü bir şekilde uzak kullanıcılar tarafından belirli parametreler doğrultusunda kullanılabilir ve faydalanılabilir [4]. Uygulama Programlama Arayüzü eş zamanlı olarak bir verinin işlenmesine olanak sağlar. Örnek vererek açıklamak gerekirse; bir yolcu havalimanında bir mağazanın yanından geçerken bluetooth verisi sayesinde eşzamanlı olarak telefonuna o mağazanın indirim bilgileri alabilir. API sayesinde bu bilgiler yolcuya yönlendirilebilir. Bu şekilde işletmeler, eşzamanlı olarak pazarlama faaliyetlerini gerçekleştirebilir. API işlemlerin hızlı ve pratik olmasını 
sağlar. API'lerin kullanımı havacılık sektöründe yaygınlaşmaktadır [5].

Özellikle "Total Airport Management" ve "Collaborative Decision Making” gibi konseptler üzerine inşa edilmiş çok sayıda havacılık paydaşının ve sisteminin birbirleri ile etkileşim içinde bulunduğu ekosistemlerde API kullanımı veri paylaşımında avantaj yaratmaktadır [6][7].

\subsection{Yapay Zeka}

Whitby, yapay zekayı şoyle tanımlamaktadır: "İnsanlarda, hayvanlarda ve makinelerde zeki davranışın ne olduğunu inceleyen ve insan yapımı aygıtların nasıl bu tip davranışlar sergileyebileceğini bulmaya çalışan bir bilim dalıdır (Whitby, 2005, s. 17). Whitby, aynı zamanda, insanlığın bugüne kadarki en zor ve en heyecan verici girişimi olduğunu da düşünmektedir [8].

Yapay zeka giderek çoğalan ve gelişen sistemlerin bütünüdür. Her geçen zaman, sistemin gelişmesi ile birlikte yeni alt sistemsel kavramları da beraberinde getirmektedir. Bu alt sistemlerin, yani yapay zekanın alt dallarının sayısı giderek artmaktadır. Bunlardan bazıları ; Yapay Sinir Ağları, Uzman Sistemler (Expert Systems), Makine Öğrenme (Machine Learning), Bulanık mantık (Fuzzy Logic), Doğal Dil İşleme (Natural Language Processing) ve Robotik Sistemlerdir [9].

\section{Yapay Zekanın Alt Dalları}

\subsection{Yapay Sinir A Ăları}

Yapay Sinir Ağları kullanım alanlarına ; rota belirleme, parmak izi okuma, yüz tanıma, ses tanıma, gibi örnekleri vermemiz mümkündür [10]. Ayrıca yapay sinir ağları kullanılarak havacılığın bir çok alanındaki karmaşık problemler de çözüme kavuşturulabilmektedir:

- Uçaklar için yedek parça talebinin tahmin edilmesi [11]

- Yolcu bagajlarındaki yasa dışı nesnelerin tespit edilmesi [12]

- Uçuş sırasında kanatta ve kuyrukta oluşan uçak içi yüklere bağlı etkilerin analizi [13]

\subsection{Uzman Sistemler}

Uzman Sistemler; tanı, analiz, izleme, danışma, fikir verme, plan gibi pek cok konuda kullanılmaktadır. Uzman sistemler, insana tavsiyede bulunma, insanı yönlendirme ve destekleme, insanı temsil etme, bir çözüm elde etme, sorunu teşhis etme, sonuçları tahmin etme gibi çok sayıda alternatif çözümler önerme becerisine sahiptir [14]. Havacılık faaliyetleri yoğun bilgi birikimi gerektirdiği için uzman sistemler hem uçak bakımları sürecinde hem de havalimanı pistlerinin deformasyonunun tespitinde kullanılabilmektedir [15][16].

\subsection{Bulanık Mantık (Fuzzy Logic)}

Bulanık mantığın kullanım alanlarına örnek olarak; oda 1dığının gün 1şığı doğrultusunda ayarlanması, şeker hastalarının insulin miktarını dengelleyen aletler verilebilir. Ayrıca 1987 yılında Hitachi firması tarafindan Sendai Metrosuna bulanık mantık sistemi ile trenin durması gereken yerde konumlanması üç kat daha iyi hale gelmiş ve \%10 enerji tasarufu sağlanmıştır [17]. Bu 
çalışmada Bulanık Sistem Teknolojisine başarılı örneklerden biri olarak gösterilebilir. Ayrıca, Belgrad Havalimanı'nda yapılan bir çalışma ile yolculuk tahminlemesi yaparak hangi noktaya kaç yolcunun seyahat etmek isteyeceği de tahminlenmiş ve faydalı sonuçlar elde edilmiştir [18]. Çeşitli insansız hava araçlarının kontrol ünitelerinde de kullanılan Fuzzy Logic navigasyon fonksiyonlarının gerçekleştirilmesine de yardımcı olabilmektedir [19][20].

\subsection{Makine Öğrenmesi (Machine Learning)}

Online çalışan birçok uygulama makine öğrenimini şuan kullanmaktadır. Örneğin; Facebook size zaman tünelinde ne göstereceğini bu algoritma ile karar veriyor, Amazon hangi ürünlerini tavsiye edeceğini, Netflix hangi fimleri önereceğini yine makine öğrenimi ile karar veriyor. Şirketler, ellerindeki mevcut verilere göre sizin nelerden hoşlanacağınızı tahmin edip ona göre karar veriyor ve hizmet sağliyorlar.

Havacılıkta makine öğrenmesi tekniğinin çok geniş kullanım alanları mevcuttur. Örneğin, makine öğrenmesi ile türbülans analizi yapabilir, terminal içinde ve dışında insanların, yer hizmeti araçlarının ve uçakların fiziksel konumlarını takip edebilirsiniz [21][22]. Fakat makine öğrenmesinin en büyük etki sağladığı nokta uçuş ekseninde elde edilen tahminlemelerdir. Çok sayıda paydaşın katılım sağladığı uçuş operasyonlarında uçuşların ne kadar gecikeceğini bilmek havalimanı verimliliğini birçok noktada artırmaktadır [23]. Ayrıca, gecikmenin tahmini gibi bir uçuşa ne kadar yolcunun geleceği, yolcuların havalimanına hangi zaman diliminde geleceği, uçuşta ne kadar yolcu yükü oluşacağı gibi çok sayıda uçuş parametresi de makine öğrenmesi ile tahminlenebilmektedir. Havacılık için müşteri memnuniyetini artırmanın bir diğer yolu da bagaj kayıplarını azaltmaktan geçer ve makine öğrenmesi tekniği ile riskli bagajlar tespit edilerek operasyon görevlilerine özel önlem almaları için bildirilebilir [24].

\subsection{Doğal Dil İşleme (Natural Language Processing)}

Yapay zekanın bir diğer dalı olan doğal dil işleme ; doğal dili anlama, çözümleme, yorumlama ve üretmenin bütünüdür. Bu sistem sayesinde ; metinlerin otomatik olarak başka bir dile çevrilmesi, yazılanların sesli olarak okunabilmesi gibi birçok işlev gerçekleştirilebilmektedir. Büyük veri teknolojilerine yatırım yapmakta olan şirketler, ellerindeki büyük veri metinlerini analiz etmesi için bu sistemi kullanmaktadır [25]

\section{Robotik Sistemler}

Bu alandaki uygulamalar oldukça çeşitlidir. Havalimanlarında halihazırda uygulanmış olan gerçek iş çözümlerini inceleyerek daha fazla bilgi sahibi olabiliriz;

\subsection{Robotik Kiosklar}

Havaalanlarında yoğun veya kalabalık alanlara otonom olarak ve ekipler halinde hareket edebilen akıllı check-in kioskları robotik kiosklara örnektir [26] Uçuş ve yolcu akış bilgileri, ek check-in kiosklarının ne zaman ve nerede gerekli olduğunu algılamak için bu kiosklardan yararlanılabilir. 


\subsection{Otonom Elektrikli Süpürgeler}

Havaalanı Temizleme Robotu, çöpleri vakumlayarak havaalanında dolaşan kameralar, 1şık sensörleri ve sensör yüklü tamponlarla donatılmış büyük bir elektrikli süpürgedir. Temizleme robotu, veritabanındaki havaalanının haritasını kullanarak temizlik için en iyi rotayı seçerek bağımsız olarak hareket edebilir [27].

\subsection{Güvenlik Robotları}

Schenzen Havalimanında Anbot güvenlik robotu, yolcuların fotoğraflarını çekebilen ve güvenlik istasyonlarında analiz için gönderebilen yüz tanıma yazılımına sahip dört yüksek çözünürlüklü kamera ile donatılmıştır [28]. Ayrıca kayıp yolculara yön verebilir, yangınları tespit edebilir ve hava kalitesini izleyebilir. Şüpheli bir durum olması durumunda (şüpheli ses ve 1şık), sorunu kontrol odası memuruna aktararak onay aldığı takdirde elektroşok silahlarını etkinleştirebilir. Shenzen Havalimanında bu güvenlik robotu aktif olarak kullanılmaktadır.

\subsection{Yolcuya Eşlik Eden Robotlar}

Schipol havalimanında bulunan Spencer; yolcuların kalkış kapılarına yönlendirmeye yardımcı olmak için tasarlanmış yolcu rehberlik robotudur [29]. Yolcu biniş kartlarını tarar ve onları doğru kalkış kapısına yönlendirir. Spencer hızını otomatik olarak yolcuların hızına göre ayarlar, engellerden kaçınır ve yolcuları kalkış kapılarına kalan mesafe hakkında bilgilendirir. Havalimanın talebi doğrultusunda bu robotlar yolculara eşlik ettiği süreç içerisinde pazarlamaya yönelik faaliyetlerde de bulunabilir. (Havalimanındaki mağazalarda bulunan indirimlerden bahsetmek vs) Varışta Spencer bunu ekranından bildirmektedir.

\subsection{Garson Robotlar}

Biber (Pepper), Oakland Havalimanında garson olarak kullanılan insansı robottur, yolculara yiyecek ve içecek seçimleri hakkında tavsiyelerde bulunmanın yanı sıra havaalanı terminal kapılarına, tuvaletlere ve bagaj talebine yön vermek üzere programlanmıştır [30] Pazarlama faaliyetlerinde en aktif kullanılan robotik sistemlerinden biridir.. Yolculara vereceği yiyecek ve içecek tavsiyelerinde reklam kullanılabilmektedir.

\section{6. Ĕ̈lence Robotlart}

San José Uluslararası Havaalanı, yolcuları 'meşgul etmek, eğlendirmek ve onlara yardım etmek' için Norma, Amelia ve Piper adında üç müşteri hizmet robotu bulundurmaktadır [31]. Robotlar, yolculara yemek ve alışveriş yerlerine eğlence ve yön vermek gibi pazarlama aktivitelerinde bulunmaktadırlar. Her robot, İngilizce, Fransızca, Almanca, Japonca ve İspanyolca dillerinde bilgi gösteren 32 inç dokunmatik tabletlerle donatılmıştır. Üç robot da dans edebilir, müzik çalabilir ve bir yolcuya e-postayla gönderilebilecek veya "yüz" ekranlarında görüntülenebilecek fotoğraflar çekebilir. Böylecek yolcuların havalimanı deneyimleri ölümsüzleştirilir.

\subsection{Sohbet Robotlart}


Havalimanlarında da sohbet robotları yolcuların sorunlarını ve taleplerini daha hızlı anlamak ve yardımcı olabilmek adına yapay zekadan yararlanmaktadır. Sohbet robotları ile yolculara kişiye özel ve anında, hızlı hizmet sunulmaktadır.

Aynı zamanda bu robotlar pazarlama aktivitesi olarak da kullanılabilmektedir, yolcuları belirli hizmetlere veya satış noktalarına yönlendirerek havalimanlarını gelirlerinin artmasına olanak sağlamaktadırlar. Bu nedenle 2020 yılı ile birlikte havayollarının \%68'i ve havalimanlarının $\% 42$ 'si sohbet robortlarının hizmetine geçiş yapmayı planlamaktadır [32].

\section{Sonuç}

Yapay Zeka, Büyük Veri ve uygulamaların birbirleri ile iletişimini kolaylaştıran API teknolojileri havacılığın geleceğini hızlı şekilde değiştiriyor. Çok sayıda yolcunun ziyaret ettiği havalimanları bu değişism rüzgarında diğer havalimanlarına öncülük etmektedir. Europol, IATA ve benzeri havacılık otoritelerinin her yıl yayınladığı raporlarda bu teknolojilerin yaygınlaşacağı konusunda ayrıntılı tahminler paylaşılmaktadır. Bu teknolojilerin doğurduğu her yeni ürün aynı zamanda havacılık ekosistemine yeni verilerin aktarılmasını sağlamaktadır ve ekosistemin büyümesi için gerekli inovasyon altyapısını sağlamaktadır. 


\section{REFERANSLAR}

[1] P.-K. V. M. F. Kalakou S, "Future airport terminals: New technologies promise capacity gains," Journal of Air Transport Management, pp. 203-212, 2015.

[2] Ö. Eğer, "Endüstri40," 5 November 2018. [Online]. Available: https://www.endustri40.com/big-datanin-buyuk-veri-endustriyel-kullanimi/.

[3] S. T. D. Merkezi, "Sivil Havacılıkta Büyük Veri Araştırma Raporu," Savunma Teknolojileri Merkezi, Ankara, 2020.

[4] Khorasani, "Artificial Intelligence: Structures and Strategies for Complex Problem Solving," Scalable Computing: Practice and Experience, vol. 9, no. 3, 2001.

[5] "Artificial Intelligence in the Aviation Manufacturing Process for Complex," in 6th International Conference on Mechanical, Materials and Manufacturing, 2019.

[6] Noyer, U., Rudolph, F., \& Jung, M. (2018). Simulating a multi-airport region on different abstraction levels by coupling several simulations. EPiC Series in Engineering, 2, 14-24.

[7] de Oliveira, Í. R., Cugnasca, P. S., Lubacheski, F. A. G., Sato, L. M., Correa, M. A., Júnior, J. B. C., ... \& Críticas, A. T. A LOGICAL ARCHITECTURE FOR DECISION-MAKING SUPPORT IN AIR TRAFFIC MANAGEMENT.

[8] W. B, Artificial Intelligence: A Beginner's Guide, Oxford: Oneworld Publications, 2003.

[9] C. E. Atalay M, "Artifical Intelligence and Machine Learning Applications in Big Data Analysis," Mehmet Akif Ersoy Üniversitesi Sosyal Bilimler Enstitüsü Dergisi, vol. 9, no. 22, pp. 155-172, 2017.

[10] O. E, Yapay Sinir Ağları, Istanbul: Papatya Yayıncılık, 2012.

[11] Sahin, M., Kizilaslan, R., \& Demirel, Ö. F. (2013). Forecasting aviation spare parts demand using croston based methods and artificial neural networks. Journal of Economic and Social Research, 15(2), 1.

[12] Muthukkumarasamy, V., Blumenstein, M., Jo, J., \& Green, S. (2004). Intelligent illicit object detection system for enhanced aviation security. In International Conference on Simulated Evolution and Learning. 
[13] Kim, D., \& Marciniak, M. (2001). A methodology to predict the empennage in-flight loads of a general aviation aircraft using backpropagation neural networks (No. DOT/FAA/AR00/50). EMBRY-RIDDLE AERONAUTICAL UNIV DAYTONA BEACH FL.

[14] Deora, V., Jindal, S., \& Jain, P. TOWARDS THE STUDY OF AN ARTIFICIAL INTELLIGENCE AND ITS RESEARCH FIELDS.

[15] Ferguson, G. R. (1983). Aircraft Maintenance Expert Systems (No. AFIT/GCS/EE/83D-9). AIR FORCE INST OF TECH WRIGHT-PATTERSON AFB OH SCHOOL OF ENGINEERING.

[16] Ismail, N., Ismail, A., \& Rahmat, R. A. O. K. (2009). Development of expert system for airport pavement maintenance and rehabilitation. European Journal of Scientific Research, 35(1), 121-129.

[17] K. E. Keskenler M, "Bulanık Mantığın Tarihi Gelişimi," Takvim-i Vekayi, vol. 5, no. 1, pp. 1-10, 2017.

[18] Kalić, M., Dožić, S., \& Babić, D. (2012). Predicting Air Travel Demand Using Soft Computing: Belgrade Airport Case Study. Compendium of papers, Euro Working Group on Transportation, Paris.

[19] Erginer, B., \& Altuğ, E. (2012). Design and implementation of a hybrid fuzzy logic controller for a quadrotor VTOL vehicle. International Journal of Control, Automation and Systems, 10(1), 61-70.

[20] Kurnaz, S., Cetin, O., \& Kaynak, O. (2009). Fuzzy logic based approach to design of flight control and navigation tasks for autonomous unmanned aerial vehicles. Journal of Intelligent and Robotic Systems, 54(1-3), 229-244.

[21] Ahmed, T. (2016). Analytics on indoor moving objects with applications in airport baggage tracking.

[22] Williams, J. K. (2014). Using random forests to diagnose aviation turbulence. Machine learning, 95(1), 51-70.

[23] Khan, W. A., Chung, S. H., \& Ma, H. L. Controlling Air Traffic Congestion By Predicting Flight Departure Delays And Duration: Integrating Machine Learning Sampling Techniques And Deep Learning Approaches. 
[24] van Leeuwen, H., Zhang, Y., Zervanou, K., Mullick, S., Kaymak, U., \& de Ruijter, T. (2020). Lost and Found: Predicting Airline Baggage At-risk of Being Mishandled. In ICAART (2) (pp. 172-181).

[25] D. K, "Büyük Veri: Önemi, Yapıs1 ve Günümüzdeki Durum," Ankara Üniversitesi Dil ve Tarih - Coğrafya Fakültesi Dergisi, vol. 56, no. 1, pp. 15-36, 2016.

[26] L. K, "The Korea Bizwire," 12 July 2018. [Online]. Available: http://koreabizwire.com/incheon-airport-introduces-airstar-passenger-aiding-robot/121298.

[27] M. J, "Newsweek," 5 June 2020. [Online]. Available: https://www.newsweek.com/pittsburgh-international-airport-tests-autonomous-cleaningrobots-ai-carnegie-robotics-1502233.

[28] "China.org.cn," 22 September 2016. [Online]. Available: http://www.china.org.cn/china/2016-09/22/content_39347636.htm.

[29] "Future Travel Experience," 16 April 2016. [Online]. Available: https://www.futuretravelexperience.com/2016/04/socially-aware-spencer-robot-guidespassengers-at-schiphol/.

[30] "Future Travel Experience," 11 January 2017. [Online]. Available: https://www.futuretravelexperience.com/2017/01/hmshost-brings-pepper-the-robot-tooakland-airport/.

[31] B. H, "USA Today," 28 October 2016. [Online]. Available: https://www.usatoday.com/story/travel/flights/todayinthesky/2016/10/28/san-jose-airportrobots $/ 92881248 /$.

[32] "CAPA," 29 Jun 2018. [Online]. Available: https://centreforaviation.com/analysis/reports/airlines-and-the-growth-of-chatbots-potentialand-brand-awareness-424982. 